\title{
AMOSTRAGEM DO MATERIAL PARTICULADO E FRAÇÃO ORGÂNICA VOLÁTIL DAS EMISSÕES EM MOTOR CICLO DIESEL SEM A UTILIZAÇÃO DE TÚNEL DE DILUIÇÃO
}

\author{
Eliana Weber de Menezes* e Renato Cataluña \\ Departamento de Físico-Química, Instituto de Química, Universidade Federal do Rio Grande do Sul, Av. Bento Gonçalves, 9500, \\ 91501-970 Porto Alegre - RS, Brasil
}

Recebido em 11/12/07; aceito em 2/6/08; publicado na web em 10/11/08

\begin{abstract}
SAMPLING OF PARTICULATE MATTER AND OF THE VOLATILE ORGANIC FRACTION OF EMISSIONS FROM A DIESEL CYCLE ENGINE WITHOUT THE USE OF DILUTION TUNNEL. Using a sampling method of particulate matter (PM) without the use of a dilution tunnel allows for evaluations of the volatile hydrocarbons (HC) in the emissions of diesel cycle engines. The procedure in this work applied a heated filter with temperature controlled. The volatile compounds are condensed at low temperature, allowing for evaluation of the $\mathrm{HC}$ by thermal desorption of the PM and for analysis of the condensed compounds of the exhaust gases.
\end{abstract}

Keywords: diesel; sampling of particulate matter; sampling of volatile organic fraction.

\section{INTRODUÇÃO}

Devido ao grande número de veículos automotores nos grandes centros urbanos, a contaminação do ar tem atingido níveis alarmantes. Os veículos equipados com motores ciclo diesel são responsáveis pela maior parte das emissões de material particulado (MP), óxidos de nitrogênio $\left(\mathrm{NO}_{\mathrm{x}}\right)$ e óxidos de enxofre $\left(\mathrm{SO}_{x}\right) \cdot{ }^{1-5} \mathrm{~A}$ imposição de limites máximos para as emissões dos motores diesel está associada aos danos provocados à saúde e ao meio ambiente pelo material particulado e óxidos de nitrogênio. No caso do material particulado, o perigo está associado ao seu pequeno tamanho (diâmetro aerodinâmico médio na faixa de $0,01-0,25 \mu \mathrm{m}),{ }^{6,7}$ grande área superficial e compostos orgânicos adsorvidos. ${ }^{7-10} \mathrm{O}$ material particulado, gerado na combustão do óleo diesel, contém sulfatos, nitratos, metais pesados e hidrocarbonetos policíclicos aromáticos..$^{11}$ Devido ao seu pequeno tamanho, o material particulado é facilmente inalado através das vias respiratórias, podendo acumular-se nos alvéolos pulmonares, causando fibrose, efeitos mutagênicos e aumento da incidência de câncer pulmonar. ${ }^{12-19}$

Os hidrocarbonetos (HC) das emissões do diesel são compostos de elevada massa molar, gerados a partir da combustão incompleta do óleo diesel e do óleo lubrificante. ${ }^{2,3,8}$ Estes ficam adsorvidos sobre a superfície do material particulado, gerando agregados. A aglomeração dos núcleos carbônicos, contendo hidrocarbonetos adsorvidos, começa na câmara de combustão e continua até a descarga. Os hidrocarbonetos não queimados apresentam maiores concentrações nas regiões frias da câmara de combustão, ou seja, junto às paredes, ou na região onde a mistura é muito diluída, impedindo a propagação da chama. ${ }^{20}$ Também ocorre a presença dos hidrocarbonetos no início e no final da injeção por baixa velocidade, com conseqüente má mistura, e pelo combustível retido na cavidade fria do bico injetor. ${ }^{21}$

A formação do material particulado gerado na combustão do diesel é bastante complexa e envolve uma seqüência de etapas reacionais (pirólise, nucleação, crescimento e coagulação, agregação e oxidação). ${ }^{22}$ Além disso, depende de vários fatores, como tipo de motor, condições de operação e composição do combustível. ${ }^{23} \mathrm{~A}$

*e-mail:eliana@iq.ufrgs.br quantificação do material particulado depende diretamente do seu sistema de amostragem. Segundo a norma técnica NBR $14489,{ }^{24} \mathrm{o}$ material particulado é definido como qualquer material coletado nos filtros do sistema de amostragem, após a diluição do gás de exaustão bruto do motor com o ar limpo e filtrado. A determinação da emissão de material particulado requer um sistema de diluição capaz de manter a temperatura do gás de exaustão diluído, no máximo, a 325 K (52 ${ }^{\circ} \mathrm{C}$ ) e prevenir a condensação de água. Todas as partes do sistema de diluição e do sistema de amostragem (do tubo de escapamento até o suporte do filtro), que estão em contato com o gás de exaustão bruto e diluído, devem ser projetadas para minimizar a deposição ou a alteração do material particulado.

Este trabalho apresenta resultados da quantificação do material particulado do diesel, sem a utilização do túnel de diluição. O procedimento utilizado permite a condensação dos hidrocarbonetos voláteis dos gases de exaustão, o que não é possível utilizando-se o túnel de diluição. O sistema de amostragem foi desenvolvido para a quantificação do material particulado e análise dos hidrocarbonetos voláteis condensados sobre os núcleos carbônicos do material particulado e na fração condensada dos gases de exaustão. O procedimento proposto utiliza um filtro com temperatura controlada e um condensador com água gelada e avalia os hidrocarbonetos em um amplo espectro, através da dessorção térmica do material particulado e análise da fração condensada dos gases de exaustão do motor diesel.

\section{PARTE EXPERIMENTAL}

\section{Materiais}

Os ensaios para quantificação do material particulado e análise dos hidrocarbonetos voláteis das emissões da combustão do diesel foram realizados utilizando-se um motor/gerador Diesel Toyama, modelo T 70F, estacionário, monocilindro, quatro tempos, com injeção direta de combustível e taxa de compressão de 17:1. O motor/gerador operou a $3600 \mathrm{rpm}$ e carga fixa de $2000 \mathrm{~W}$. Como combustível, utilizou-se um diesel comercial fornecido pela Petrobras (Petróleo Brasileiro S.A), cujas propriedades físico-químicas foram determinadas em laboratório através de ensaios padronizados, conforme os resultados apresentados na Tabela 1. 
Tabela 1. Propriedades físico-químicas do diesel

\begin{tabular}{lcc}
\hline Propriedades & Diesel & ASTM \\
\hline Enxofre total (\% massa) & 0,0444 & D 5453 \\
Destilação: $50 \%$ vol., recuperado $\left({ }^{\circ} \mathrm{C}\right)$ & 268,2 & D 86 \\
Destilação: $85 \%$ vol., recuperado $\left({ }^{\circ} \mathrm{C}\right)$ & 342,4 & D 86 \\
Massa específica a $20{ }^{\circ} \mathrm{C}\left(\mathrm{kg} / \mathrm{m}^{3}\right)$ & 840,8 & D 4052 \\
Ponto de Fulgor $\left({ }^{\circ} \mathrm{C}\right)$ & 47 & D 93 \\
Ponto de entupimento de filtro a frio $\left({ }^{\circ} \mathrm{C}\right)$ & +1 & D 6371 \\
Ponto de névoa $\left({ }^{\circ} \mathrm{C}\right)$ & 6,0 & D 2500 \\
Ponto de fluidez $\left({ }^{\circ} \mathrm{C}\right)$ & $-3,0$ & D 97 \\
Resíduo de carbono Ramsbottom & 0,13 & D 524 \\
Viscosidade cinemática $\left(\mathrm{mm}{ }^{2} / \mathrm{s}=\mathrm{cSt}\right)$ & 3.2 & D 445 \\
Número de cetano & 47 & D 613 \\
Entalpia de combustão $(\mathrm{MJ} / \mathrm{kg})$ & 46,4 & D 240 \\
Fórmula molecular média* & $\mathrm{C}_{13} \mathrm{H}_{29}$ & - \\
Massa molar média $(\mathrm{g} / \mathrm{mol}) *$ & 185 & - \\
\hline
\end{tabular}

* Determinada por cromatografia gasosa com detector de ionização de chama (GC-FID).

\section{Métodos}

Amostragem do material particulado e análise dos hidrocarbonetos adsorvidos

A amostragem do material particulado da exaustão do motor diesel foi realizada através da passagem de um fluxo constante de 8,0 $\mathrm{L} / \mathrm{min}$ em um suporte contendo um filtro (microfiltro de fibra de vidro com $47 \mathrm{~mm}$ de diâmetro, Macherey-Nagel ${ }^{\circledR}$ ). A medida do fluxo dos gases foi obtida utilizando-se um medidor de fluxo mássico $(20 \mathrm{~L} /$ min, Sensirion ${ }^{\circledR}$ ), e a temperatura do suporte foi ajustada através de um forno com controle eletrônico de temperatura. O tempo de amostragem do material particulado por filtro foi de $30 \mathrm{~min}$ e os ensaios foram realizados de forma a obter no mínimo cinco resultados com desvio padrão menor do que $5 \%$ do valor médio obtido.

Após a retenção do material particulado no filtro, os gases são resfriados em um condensador de vidro, com água na temperatura de $5{ }^{\circ} \mathrm{C}$. A Figura 1 apresenta o esquema da amostragem do material particulado.

A quantificação do material particulado foi realizada por análise gravimétrica, em função do volume de gás amostrado. Para a análise gravimétrica, utilizou-se uma balança analítica com precisão de 0,0001 g (Ohaus, AS 2005). A amostragem do material particulado foi realizada com o suporte nas temperaturas de 100 e $300^{\circ} \mathrm{C}$.

Os compostos orgânicos voláteis do material particulado foram obtidos por dessorção térmica do material retido no filtro. A fração dessorvida foi calculada através da variação da massa de material particulado antes e após o procedimento de dessorção. A dessorção térmica foi realizada sob fluxo de argônio $(20 \mathrm{~mL} / \mathrm{min})$, com taxa de aquecimento de $10^{\circ} \mathrm{C} / \mathrm{min}$, desde a temperatura ambiente até $550^{\circ} \mathrm{C}$. O elemento filtrante, com massa conhecida de material particulado, foi colocado em um tubo de quartzo, com saída para a atmosfera. Os compostos voláteis do material particulado, condensados na superfície interna fria do tubo de quartzo, foram solubilizados com 3,0 mL de diclorometano $\left(\right.$ Merck $\left.^{\circledR}\right)$ e avolumados, sob fluxo de argônio, para $1,0 \mathrm{~mL}$. A composição do produto foi analisada por cromatografia gasosa com detector de ionização de chama.

A análise cromatográfica foi realizada utilizando-se uma coluna capilar HP-5 (5\% fenilmetilsiloxano) com $30 \mathrm{~m}$ x 0,32 mm x 0,25 $\mu \mathrm{m}$. As temperaturas do injetor e do detector foram de 250 e 310 ${ }^{\circ} \mathrm{C}$, respectivamente. $\mathrm{O}$ volume de amostra injetado foi de $2,0 \mu \mathrm{L}$, com injeção automática e razão de split de 1:10. O fluxo de gás na

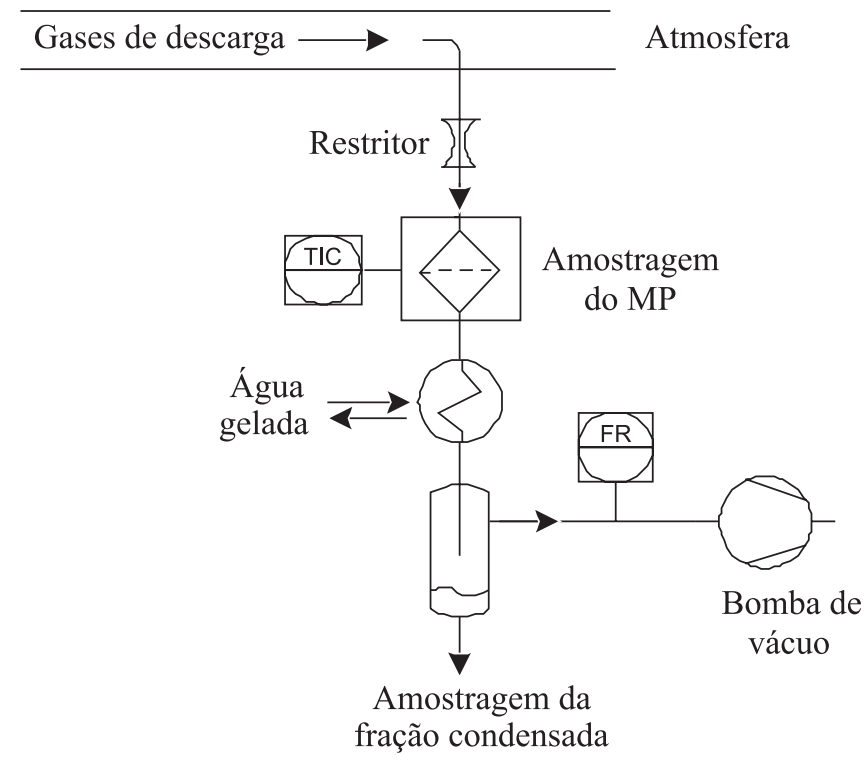

Figura 1. Amostragem do material particulado (MP) e da fração líquida condensada dos gases de exaustão. TIC = controlador e indicador de temperatura $F R=$ registrador de fluxo

coluna foi de $1,0 \mathrm{~mL} / \mathrm{min}$. A programação de aquecimento do forno partiu de $80{ }^{\circ} \mathrm{C}$, seguido de $3{ }^{\circ} \mathrm{C} / \mathrm{min}$ até $300{ }^{\circ} \mathrm{C}$, permanecendo 5 min nesta temperatura. Utilizou-se hélio $99,99 \%$ de pureza como gás de arraste.

Para a identificação dos hidrocarbonetos voláteis do material particulado, utilizou-se um padrão de hidrocarbonetos parafínicos lineares na faixa do diesel contendo 9 a 30 átomos de carbono $\left(\right.$ Supelco $\left.^{\circledR}\right)$

\section{Amostragem dos hidrocarbonetos da exaustão}

Os hidrocarbonetos resultantes da combustão incompleta do diesel foram amostrados na saída do condensador em um vaso separador, conforme a Figura 1. A composição do condensado foi determinada utilizando-se micro-extração em fase sólida (SPME) no headspace e cromatografia gasosa com detector de massas (GC-MS, Varian - Saturn 2100).

Dois mililitros $(2,0 \mathrm{~mL})$ do condensado foram colocados em um frasco SPME de $15 \mathrm{~mL}$ (Supelco ${ }^{\circledR}$ ), tampado hermeticamente. A SPME foi realizada utilizando-se uma fibra de $100 \mu \mathrm{m}$ de polidimetilsiloxano (PDMS) (Supelco ${ }^{\circledR}$ ). Para a extração, a fibra foi exposta na fase gasosa (headspace) da amostra (imersa em um banho termostatizado na temperatura de $60{ }^{\circ} \mathrm{C}$ ) durante $60 \mathrm{~min}$. Após a exposição, a fibra foi retraída e imediatamente introduzida no injetor do cromatógrafo para a dessorção. O período da dessorção térmica no injetor foi de $30 \mathrm{~min}$.

A análise cromatográfica foi realizada utilizando-se uma coluna capilar CP SIL 8 CB Low Bleed ( $30 \mathrm{~m}$ x 0,25 mm x 0,25 $\mu \mathrm{m}$ ). As temperaturas do injetor e da interface coluna/detector foram de $230 \mathrm{e}$ $170{ }^{\circ} \mathrm{C}$, respectivamente. As condições de análise no GC foram: fluxo de gás na coluna igual a 1,0 mL/min, modo de injeção com pulso de pressão igual a 10 psi durante $0,25 \mathrm{~min}$, temperatura do injetor igual a $230{ }^{\circ} \mathrm{C}$, injeção em modo splitless e após $0,50 \mathrm{~min}$ com razão de split de 1:10. A programação de aquecimento do forno partiu de uma isoterma a $40{ }^{\circ} \mathrm{C}$ durante $4 \mathrm{~min}$, com taxa de aquecimento $1{ }^{\circ} \mathrm{C} / \mathrm{min}$ até $230{ }^{\circ} \mathrm{C}$, somando o tempo total de 190 min de corrida. O MS foi executado em modo scan, com varredura de íons com massa/ carga $(\mathrm{m} / \mathrm{z})$ de 45 a 400 . Utilizou-se hélio $99,99 \%$ de pureza como gás de arraste. 


\section{RESULTADOS E DISCUSSÃO}

O sistema de amostragem para a quantificação do material particulado foi desenvolvido para avaliar os hidrocarbonetos condensados no material particulado e nos gases de exaustão do motor diesel. O procedimento controla a temperatura de amostragem do material particulado e condensa a fração volátil dos gases de exaustão.

O túnel de diluição com ar atmoférico, segundo a norma NBR $14489,{ }^{24}$ serve para baixar a pressão parcial dos gases e evitar a condensação de compostos voláteis no sistema. Neste trabalho, o fluxo dos gases de exaustão passa diretamente através do filtro com controle de temperatura, sem o resfriamento proporcionado pelo sistema de diluição. Desta forma, há um aumento da pressão de vapor dos hidrocarbonetos, favorecendo a condensação destes no material particulado e condensador. Este procedimento permite avaliar os hidrocarbonetos através da dessorção térmica do material particulado e da análise da fração líquida dos gases de exaustão. Adicionalmente, avaliou-se o efeito da temperatura de amostragem na quantificação do material particulado, na fração dessorvida do material particulado e na composição da fração líquida dos gases de exaustão.

A Tabela 2 apresenta a concentração de material particulado na exaustão e a fração de hidrocarbonetos voláteis condensados no material particulado em função da temperatura de amostragem. Os valores correspondem à média de 5 amostragens, e os valores entre parênteses, ao desvio padrão correspondente.

Tabela 2. Material particulado (MP) $\left(\mathrm{mg} / \mathrm{m}^{3}\right)$ e compostos dessorvidos do MP $\left(\mathrm{mg} / \mathrm{m}^{3}\right)$ em função da temperatura de amostragem

\begin{tabular}{lcc}
\hline $\begin{array}{l}\text { Temperatura do } \\
\text { suporte }\left({ }^{\circ} \mathrm{C}\right)\end{array}$ & $\begin{array}{c}\text { MP } \\
\left(\mathrm{mg} / \mathrm{m}^{3}\right)\end{array}$ & $\begin{array}{c}\text { Compostos dessorvidos } \\
\text { do MP }\left(\mathrm{mg} / \mathrm{m}^{3}\right)\end{array}$ \\
\hline 300 & $50(3,5)$ & $9(2,5)$ \\
100 & $69(3,9)$ & $47(7,5)$ \\
\hline
\end{tabular}

Comparando-se a massa de material particulado nas temperaturas de amostragem de 100 e $300^{\circ} \mathrm{C}$, observa-se que com baixa temperatura $\left(100{ }^{\circ} \mathrm{C}\right)$ a massa de material particulado é cerca de $30 \%$ maior que a massa de material particulado amostrado a $300{ }^{\circ} \mathrm{C}$.

Os hidrocarbonetos com baixa pressão de vapor, sulfatos, ácido sulfúrico e água começam a adsorver-se sobre o material particulado enquanto ainda estão dentro da câmara de combustão e continuam a adsorver-se conforme os componentes da exaustão são resfriados, devido ao contato com as partes frias da tubulação. Para a amostragem a $100^{\circ} \mathrm{C}$, os hidrocarbonetos de maior massa molar condensam nos núcleos carbônicos aumentando a massa de material particulado. Nesta temperatura ocorre também a condensação nas paredes frias do suporte. Com amostragem a $300{ }^{\circ} \mathrm{C}$ (próximo da temperatura da descarga do motor) a fração de hidrocarbonetos condensados no filtro, suporte e tubulação é menor.

A Figura 2 apresenta a distribuição dos hidrocarbonetos dessorvidos do material particulado, com amostragem a $100{ }^{\circ} \mathrm{C}$.

Conforme a Figura 2, os compostos dessorvidos do material particulado do diesel caracterizam-se basicamente como hidrocarbonetos saturados de elevada massa molar, contendo de 16 a 30 átomos de carbono, indicando que a fração volátil do material particulado é formada, em grande parte, pela fração de compostos pesados que compõem o óleo diesel e o óleo lubrificante. Quanto maior a massa molar, maior é a entalpia de vaporização, dificultando a oxidação destes compostos. Com amostragem a $300{ }^{\circ} \mathrm{C}$, a distribuição dos compostos é a mesma, porém com menor intensidade dos sinais, devido a menor fração de hidrocarbonetos condensados nos núcleos carbônicos.

A composição da fração condensada dos gases de exaustão é

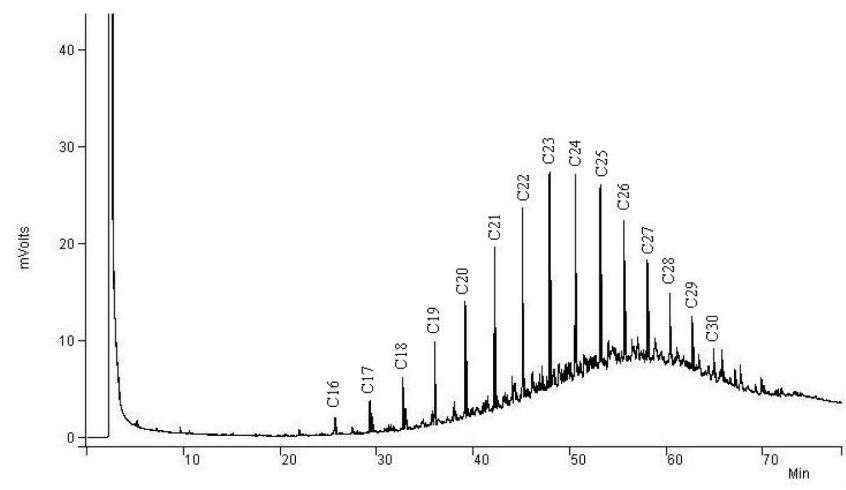

Figura 2. Distribuição dos hidrocarbonetos dessorvidos do material particulado com amostragem a $100{ }^{\circ} \mathrm{C}$ e identificação dos compostos com padrão de hidrocarbonetos parafínicos na faixa do diesel

influenciada pela temperatura do filtro que retém o material particulado. Com a temperatura do filtro a $300{ }^{\circ} \mathrm{C}$ (próximo da temperatura da descarga do motor), maior é a concentração de hidrocarbonetos recolhidos no condensador. Com baixa temperatura, ocorre maior condensação de hidrocarbonetos nos núcleos carbônicos do material particulado e suporte do filtro, diminuindo a concentração destes na água.

A Figura 3 apresenta o perfil cromatográfico da distribuição dos compostos presentes na fração condensada do diesel, utilizando-se o suporte a $300{ }^{\circ} \mathrm{C}$.

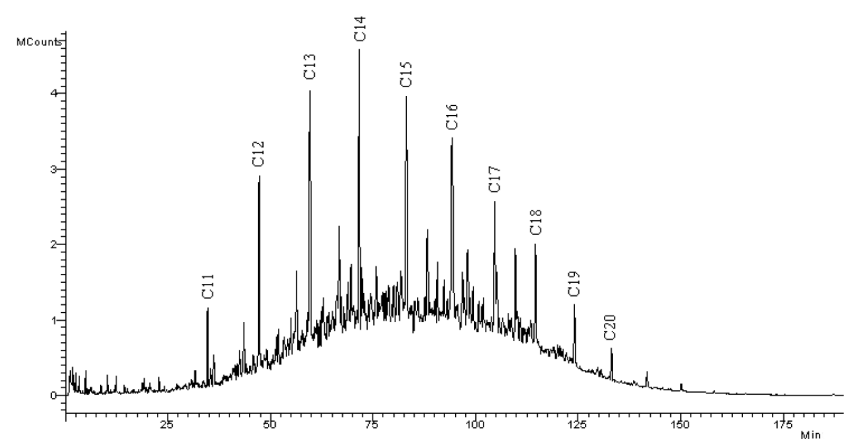

Figura 3. Distribuição dos compostos da fração condensada dos gases de exaustão do motor diesel com amostragem a $300{ }^{\circ} \mathrm{C}$ e identificação com padrão de hidrocarbonetos parafínicos na faixa do diesel

De acordo com a Figura 3, os hidrocarbonetos voláteis dos gases de exaustão dos motores diesel caracterizam-se como compostos contendo de 11 a 20 átomos de carbono. Estes hidrocarbonetos são emitidos para a atmosfera na forma gasosa, contribuindo para a poluição fotoquímica.

\section{CONCLUSÕES}

O procedimento de amostragem do material particulado e hidrocarbonetos voláteis da exaustão dos motores diesel, sem o resfriamento proporcionado pelo túnel de diluição, permite avaliar os hidrocarbonetos presentes na fração orgânica volátil do material particulado, bem como os hidrocarbonetos voláteis dos gases de exaustão, correlacionando-os com a qualidade do diesel e com a eficiência do processo de combustão. A utilização deste procedimento possibilita a otimização de combustíveis e motores para a redução da contaminação ambiental.

Os hidrocarbonetos oriundos da combustão do diesel são emitidos ao meio ambiente condensados no material particulado e na forma gasosa. Durante as fases de combustão e descarga, os hidrocarbonetos 
de maior massa molar condensam sobre os núcleos carbônicos aumentando a massa de material particulado. A fração orgânica volátil do material particulado é composta por hidrocarbonetos na faixa de 16 a 30 átomos de carbono e os hidrocarbonetos emitidos na forma gasosa, na faixa de 11 a 20 átomos de carbono.

\section{AGRADECIMENTOS}

\section{Ao CNPq, FAPERGS e PETROBRAS.}

\section{REFERÊNCIAS}

1. Braun, S.; Appel, L. G.; Schmas, M.; Quim. Nova 2003, 27, 472.

2. Lough, C.; Christenson, C. C.; Schauer, J. J.; Tortorelli, J.; Bean, E.; Lawson, D. R.; Clark, N. N.; Gabele, P. A.; J. Air Wast Manage. Assoc. 2007, 57, 1190 .

3. Schauer, J. J.; Kleeman, M. J.; Cass, G.R.; Simoneit, B. R. T.; Environ. Sci. Technol. 1999, 33, 1578.

4. Ban-Weiss, G. A.; McLaughlin, J.P.; Harley, R. A.; Lunden, M. M.; Kirchstetter, T. W.; Kean, A. J.; Strawa, A.W.; Stevenson, E. D.; Kendall, G. R.; Atmos. Environ. 2008, 42, 220.

5. Chen, C.; Huang, C.; Jing, Q.; Wang, H.; Pan, H.; Li, L.; Zhao, J.; Dai, Y.; Huang, H.; Shipper, L.; Streets, D. G.; Atmos. Environ. 2007, 41, 5334.

6. Ntziachristos, L.; Ning, Z.; Geller, M. D.; Sheesley, R. J.; Schauer, J. J.; Sioutas, C.; Atmos. Environ. 2007, 41, 5684.

7. Harish, C. P.; Sheesley, R. J.; Fine, P. M.; Sioutas, C.; Atmos. Environ. 2007, 41, 4653 .

8. Sidhu, S.; Graham, J.; Striebich, R.; Chemosphere 2001, 42, 681.
9. Subramanian, R.; Donahue, N. M.; Bernardo-Bricker, A.; Rogge, W. F.; Robinson, A. L.; Atmos. Environ. 2006, 40, 8002.

10. Gullet, B. K.; Touati, A. ; Oudejans, L.; Ryan, S. P.; Atmos. Environ. 2006, 40, 4037.

11. Jones, C. C.; Chughtai, A. R.; Murugaverl, B.; Smith, D. M.; Carbon 2004, 42, 2471.

12. Wong, S. S.; Sun, N. N.; Keith, I.; Kweon, C. B.; Foster, D. E.; Schauer, J. J.; Witten, M. W.; Arch. Toxicol. 2003, 77, 638.

13. Dutcher, J. S.; Sun, J. D.; Lopez, J. A.; Wolf, I.; Wolff, R. K.; McClellan, R. O.; Am. Ind. Hyg. Assoc. J. 1984, 45, 491.

14. Froines, J. R; Hinds, W. C.; Duffy, R. M.; Lafuente, E. J.; Liu, W. C.; Am. Ind. Hyg. Assoc. J. 1987, 48, 202.

15. McClellan, R. O.; Am. Ind. Hyg. Assoc. J. 1986, 47, 1.

16. Steenland, K.; Deddens, J.; Stayner, L.; Am. Ind. Med. 1998, 34, 220.

17. Tokiwa, H.; Ohnishi, O.; Crit. Rev. Toxicol. 1986, 17, 23.

18. Woskie, S. R.; Smith, T. J.; Hammond, S. K.; Schenker, M. B.; Garshick, E.; Speizer, F. E.; Am. Ind. Med. 1988, 13, 381.

19. Zaebst, D. D.; Clapp, D. E.; Blade, L. M.; Marlow, D. A.; Steenland, K.; Hornung, R. W.; Scheutzle, D.; Butler, J.; Am. Ind. Hyg. Assoc. J. 1991, $52,529$.

20. Guibet, J-C.; Faure-Birchem, E.; Fuels and Engines, Technip: Paris, 1999, vol. 2, p. 421.

21. Heywood, J. B.; Internal combustion engine fundamentals, McGrawHill: New York, $1^{\text {st }}$ ed., 1988, p. 596.

22. Neeft, J. P. A.; Makkee, M.; Moulijn, J. A.; Fuel Process. Technol. 1996, 47,1 .

23. Burtscher, H.; J. Aerosol Sci. 2005, 36, 896.

24. Associação Brasileira de Normas Técnicas; NBR 14489. Motor dieselAnálise e determinação dos gases e material particulado emitidos por motores do ciclo diesel - Ciclo de 13 pontos, Rio de Janeiro, 2000. 